\title{
Effect of Current Density on Thermodynamic Properties of Nanocrystalline Palladium Capped Samarium Hydride Thin Film Switchable Mirrors
}

\author{
Pushpendra Kumar ${ }^{1,2}$ and L. K. Malhotra ${ }^{2}$ \\ ${ }^{1}$ Technische Physik, Universität des Saarlandes, Geb. 38, Postfach 151150, 66041 Saarbrücken, Germany \\ ${ }^{2}$ Thin Film Laboratory, Department of Physics, Indian Institute of Technology, Hauz Khas, New Delhi 110016, India
}

Received 20 November 2006; Accepted 12 December 2006

Recommended by Rakesh K. Joshi

\begin{abstract}
A $55 \mathrm{~nm}$ samarium film capped with a $10 \mathrm{~nm}$ palladium overlayer switched from a metallic reflecting to a semiconducting, transparent in visible state during ex-situ hydrogen loading via electrochemical means in $1 \mathrm{M} \mathrm{KOH}$ electrolytic aqueous solution at room temperature. The switching between metal to semiconductor was accompanied by measurement of transmittance during hydrogen loading/unloading. The effect of current density on switching and thermodynamic properties was studied between dihydride state (FCC phase) and trihydride state (hexagonal phase). From the plateau of partial pressure of hydrogen at $x=2.6$, enthalpy of formation was calculated at different current densities. The diffusion coefficients and switching kinetics are shown to depend on applied current density.
\end{abstract}

Copyright ( 2007 P. Kumar and L. K. Malhotra. This is an open access article distributed under the Creative Commons Attribution License, which permits unrestricted use, distribution, and reproduction in any medium, provided the original work is properly cited.

\section{INTRODUCTION}

Hydrogen in metal has been the subject of extensive research because of their intriguing physical and chemical properties [1]. Recently, Huiberts et al. [2] have discovered electrical and optical switching in yttrium and lanthanum thin film just by varying the hydrogen concentration. This switchable mirror effect has since received a lot of attention both from fundamental physics [3-5] point of view as well as its technological applications in smart windows, hydrogen sensors, solid-state displays, and electrochromic devices [6]. It is now known that almost all rare earth metals and rare earth-based alloys exhibit this effect [7-14]. Hydrogenation of palladiumcapped thin films of these materials can be achieved by exposing the sample to a hydrogen gas atmosphere [15-20], electrochemically by polarization in a suitable electrolyte solution [21-23] or chemically by immersion in a $\mathrm{NaBH}_{4}$ solution [24]. Because of the hazards involved in handling hydrogen gas [25], and the difficulty in continuously monitoring the amount of hydrogen getting incorporated into the films, gas phase loading is not very practical from the application point of view. These issues can be taken care of by hydrogenation via electrochemical means. Electrochemical loading offers many advantages: the concentration of hydrogen in the film can be controlled accurately, extremely low pressure can be achieved and electrochemical potential is related to an effective hydrogen gas pressure, thereby offering the possibility to study the thermodynamic properties of the system. Drastic changes in optical properties have been observed in cases where there is a structural transition in going from the dihydride to trihydride state as well as in cases where the structure remains unaffected confirming thereby that the phenomenon is of electronic origin [3]. In this study, we report the thermodynamic properties of $\mathrm{Pd} / \mathrm{Sm}$ thin film between dihydride state to trihydride state in open circuit and different anodically polarizing condition. The results are presented in this paper.

\section{EXPERIMENTAL}

Sm films of thickness $55 \mathrm{~nm}$ were deposited by vacuum evaporation on $40 \mathrm{~mm} \times 40 \mathrm{~mm} \times 2 \mathrm{~mm}$ ultrasonically cleaned glass substrates. The base pressure in the vacuum system was $7 \times 10^{-5} \mathrm{~Pa}$ prior to deposition. Pd overlayer of thickness $10 \mathrm{~nm}$ was deposited on top of the Sm films without breaking the vacuum. The experimental details for insitu 


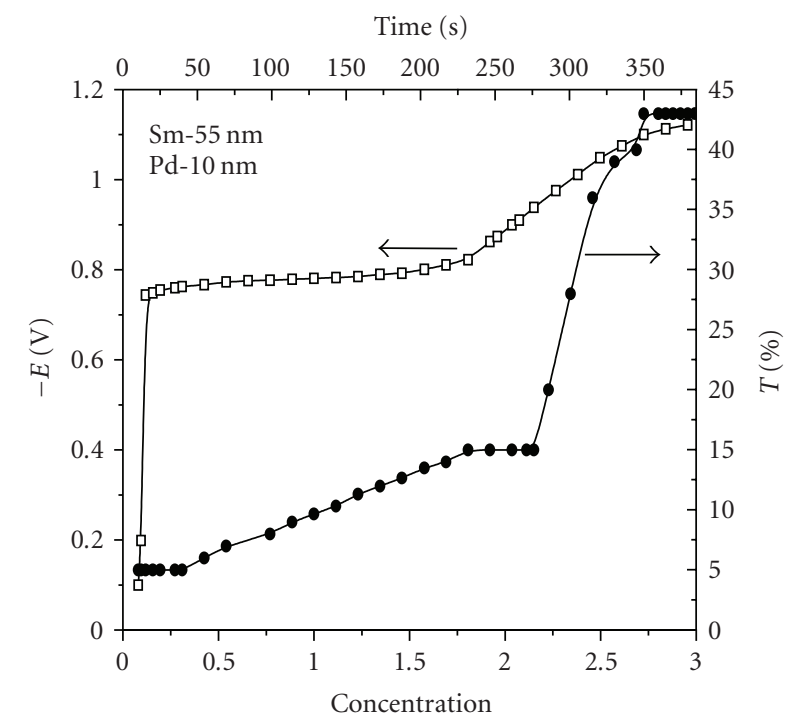

Figure 1: Change of the electrode potential and transmission of Pd $(10 \mathrm{~nm})$ capped Sm film $(55 \mathrm{~nm})$ on hydrogen loading at $0.2 \mathrm{~mA} / \mathrm{cm}^{2}$ as a function of hydrogen concentration $x=\mathrm{H} / \mathrm{Sm}$ determined from galvanostatic loading experiments.

measurement of film thickness and rate of deposition have been described in one of the earlier papers [26]. The galvanostatic intermittent titration technique (GITT) was used to determine the equilibrium potential as a function of hydrogen concentration in the sample. The electrochemical measurements were performed in an aqueous $1 \mathrm{M} \mathrm{KOH}$ solution using a Pt strip as a counter electrode and an $\mathrm{Hg} / \mathrm{HgO}$ electrode as a reference electrode. The effective area of palladium capped samarium films exposed to $1 \mathrm{M} \mathrm{KOH}$ electrolyte solution was $4.9 \mathrm{~cm}^{2}$ [27]. All potentials were measured with respect to the reference electrode using an electrometer (Keithley, Model-6517A) and constant current source (Keithley, Model-224) was used to apply the current. For in situ optical transmission, the Pd capped Sm film (WE) was illuminated with a diode laser (LA $12-10-650 \mathrm{~nm}$ ) and the transmission intensity measured with a photodyne radiometer/photometer (Model 88XLA), placed on the opposite end. Before each measurement, high-purity argon gas was bubbled through the solution at least for 15 minutes to remove the oxygen and a constant argon flow was maintained over the electrolyte during the measurements. Atomic force microscopy (Veeco nanoscope IIIa) was used to study the surface morphology.

\section{RESULTS AND DISCUSSION}

During electrochemical loading, the electrolytic reduction of a proton donating species, water in our case, results in the following reaction:

$$
\mathrm{H}_{2} \mathrm{O}+\mathrm{e}^{-} \longrightarrow \mathrm{H}_{\mathrm{ad}}+\mathrm{OH}^{-} .
$$

The mechanism of hydrogen entry into palladium involves proton discharge $\mathrm{H}^{+}+\mathrm{e}^{-} \rightarrow \mathrm{H}$ followed by immediate hydrogen adsorption in the palladium layer. The adsorbed hydrogen subsequently diffuses into the underlying $\mathrm{Sm}$ film and is absorbed therein.

The reaction of hydrogen with Sm proceeds as follows:

$$
\mathrm{Sm}+\frac{3}{2} \mathrm{H}_{2} \longrightarrow \mathrm{SmH}_{2}+\frac{1}{2} \mathrm{H}_{2} \Longleftrightarrow \mathrm{SmH}_{3}
$$

The second step is a reversible transition, which can easily be induced by changing the polarity of the cell or in open circuit condition, whereas the first step is unidirectional. This is because of the relative small heat of formation for the second step $(-39.6 \mathrm{~kJ} / \mathrm{mol} \mathrm{H})$ compared to the heat of formation for the first step $(-202.6 \mathrm{~kJ} / \mathrm{mol} \mathrm{H})[11]$.

The measured electrode potential (E) between WE and reference electrode, transmittance $(\mathrm{T})$ of the $\mathrm{WE}$, as a function of hydrogen concentration getting incorporated in the WE on applying a constant current density $i=$ $0.2 \mathrm{~mA} / \mathrm{cm}^{2}$, are plotted in Figure 1. Figure 1 shows that the potential of WE drops from $-0.190 \mathrm{~V}$ to $-0.76 \mathrm{~V}$ immediately after applying the constant current. This immediate drop in potential is due to excess charge accumulated on the interface of electrolyte and WE. Three regions can thereafter be clearly distinguished: (i) a near plateau from $-0.76 \mathrm{~V}$ to $-0.81 \mathrm{~V}$, (ii) a gradual drop in potential from $-0.81 \mathrm{~V}$ to $-1.11 \mathrm{~V}$, and again (iii) a constancy at $\sim-1.11 \mathrm{~V}$. Transmittance curves taken during hydrogen loading is also shown in Figure 1. Five regions can be distinguished in the transmittance curve. $T$ is initially almost constant at $5 \%$ and then rises gradually to attain a value of $15 \%$. It again remains constant for some time followed by a sharper rise in its value to $43 \%$ and then remaining constant at that value thereafter. Since hydrogen is getting incorporated in the Sm film due to the passage of current, these changes in the two curves represent the changes taking place in Sm film due to the incorporation of hydrogen. The detailed explanation of these changes on hydrogen uptake has been discussed in one of our earlier paper [27]. Using Faraday's law and taking the film thickness, the electrode surface area, and the integrated charge into account, we have calculated the hydrogen concentration in Sm film. Based on an earlier report [28], we have taken an initial hydrogen concentration $x=0.08$, which gets incorporated into the film during deposition, into account while making our calculations. It is very important that the thickness taken into account while calculating hydrogen concentration is measured very accurately.

The working electrode was then reversibly switched, in a $1 \mathrm{M} \mathrm{KOH}$ electrolytic aqueous solution, between dihydride state (dark brownish color) and trihydride state (golden greenish color) galvanostatically at different constant current densities $\left(0.2,0.6,1.02,2.04 \mathrm{~mA} / \mathrm{cm}^{2}\right)$. A different current density was applied for different time periods to attain an appropriate amount of hydrogen in the film. Figure 2(a) shows the change in potential with time on loading of hydrogen. 


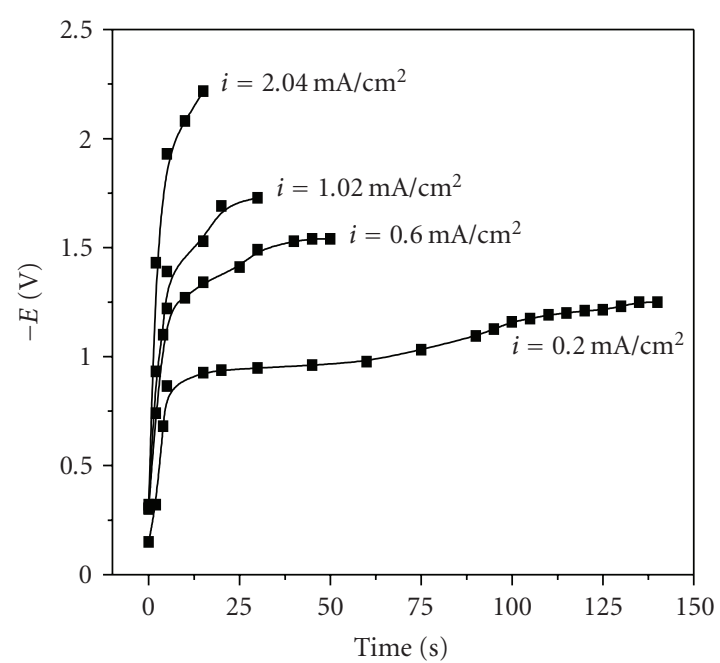

(a)

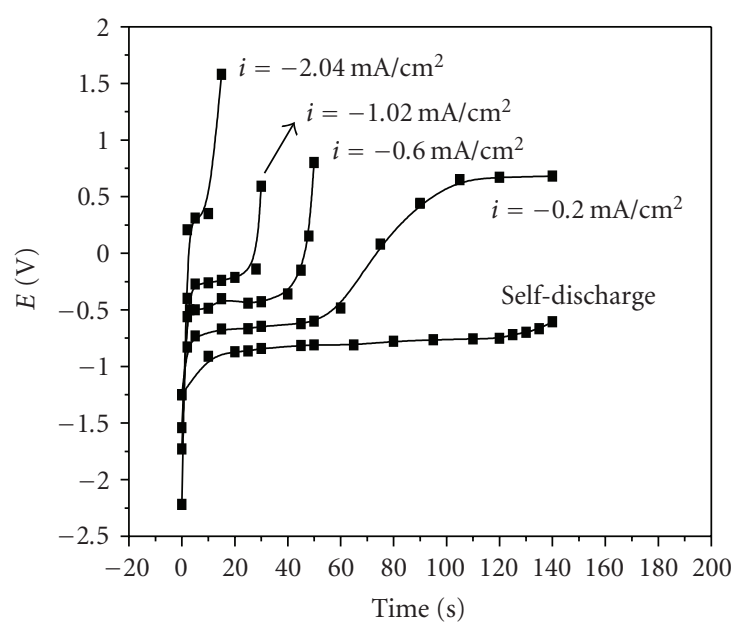

(b)

FIGURE 2: Change of the electrode potential with time for several current densities: (a) loading (b) unloading.

The fall in potential directly depends on applied current density between working and counter electrodes. If the current density is high, the rate of evolution of hydrogen ions at the electrode surface will be high, resulting in a high chemical potential generated in the solution.

The dependence of the anodic potential on applied current density with reverse polarity and in open circuit condition is shown in Figure 2(b). The shapes of unloading curves for all the current densities are very similar even though their time scales are different. The unloading of hydrogen from hydrogen saturated film $\left(\mathrm{SmH}_{3-\delta}\right)$ takes place in the plateau region, which is confirmed from the decreases in transmission in that region. The potential at which the plateau occurs shifts to positive values as the current density increases with reverse polarity. For the higher current density, the curve loses the sigmoid shape. No clear plateau occurs in loading of hydrogen, therefore, the unloading curves were used to study the thermodynamic properties.

An equilibrium hydrogen pressure $\mathrm{P}_{\mathrm{H}_{2}}$ (bar) is calculated from the equilibrium potential $E_{e}$ shown in Figure 2(b) using Nernst equation

$$
\ln \mathrm{P}_{\mathrm{H}_{2}}=-\frac{n F}{R T}\left(E_{e}+0.926\right),
$$

where $R=8.314 \mathrm{~J} / \mathrm{K} \mathrm{mol}$ is the gas constant, $F=96485 \mathrm{C} / \mathrm{mol}$ is the Faraday constant, $T$ the temperature, and $n$ the number of electrons involved in the hydrogen evolution reaction $(n=2)$. This enables us to construct the pressurecomposition isotherm for the samarium-hydrogen system between dihydride and trihydride, during hydrogen unloading. Figures 3 and 4 show the partial pressure of hydrogen and transmittance on unloading of hydrogen in open circuit condition and at different current densities, respectively. Pressure-composition isotherms also provide us information on enthalpies of formation. A plateau in the isotherm

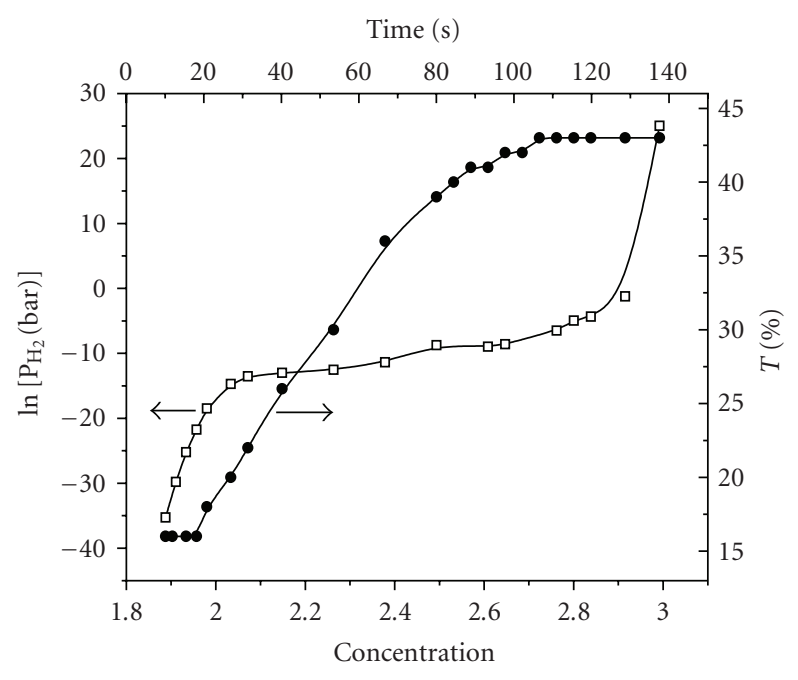

FIGURE 3: Pressure-concentration isotherm and transmission as a function of concentration during unloading in open-circuit condition.

corresponds to coexistence of two different phases, dihydride fcc and trihydride hexagonal shifts towards lower pressure with increase in applied current density during hydrogen unloading. Knowledge of these two phases, particularly those accompanying the optical change, is important for determining the mechanism of optical switching in these films. Figures 3 and 4 show the transmission of the films on unloading of hydrogen decreasing in the plateau region indicating that most of the changes in the samples take place in this region. Which can be understood by noting that in this region, the WE starts to discharge its hydrogen and that discharged hydrogen stays at the interface of WE, which is reflected in the near constant pressure of hydrogen. 


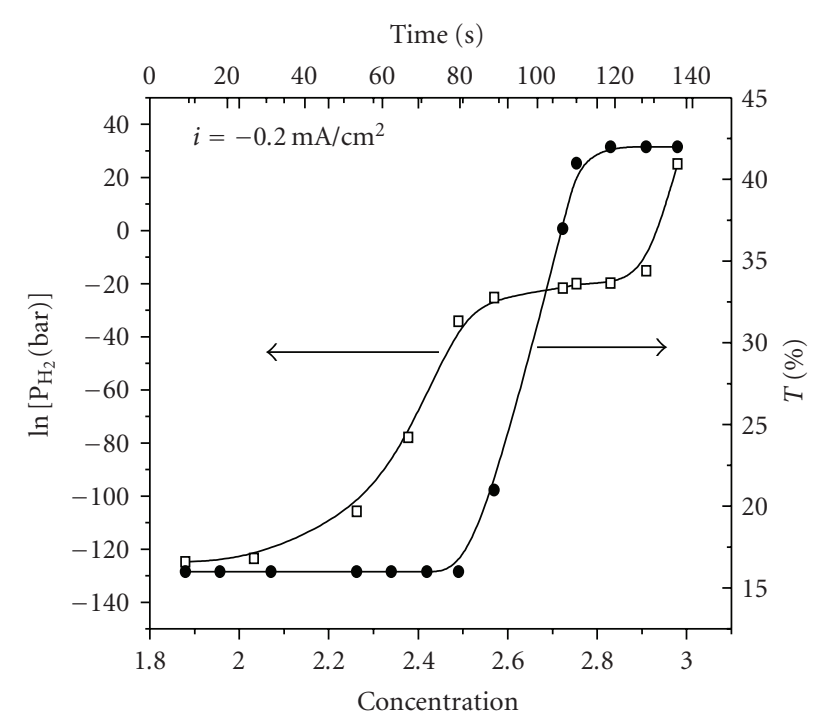

(a)

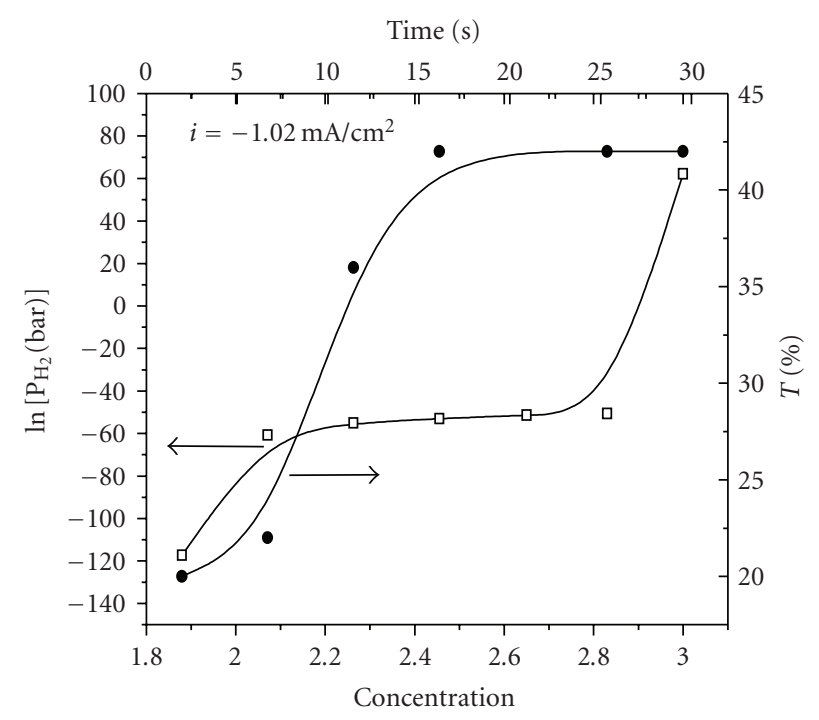

(c)

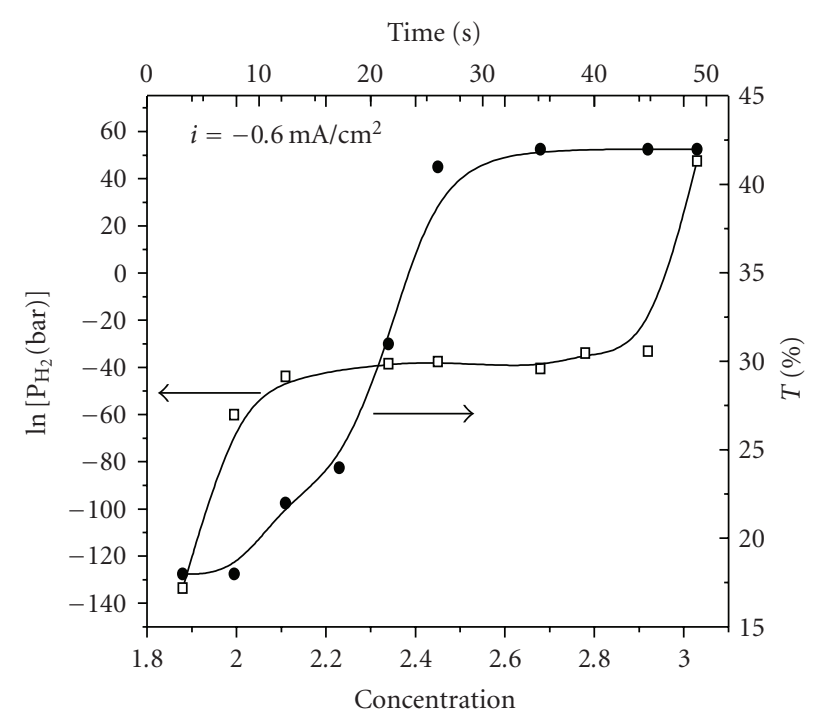

(b)

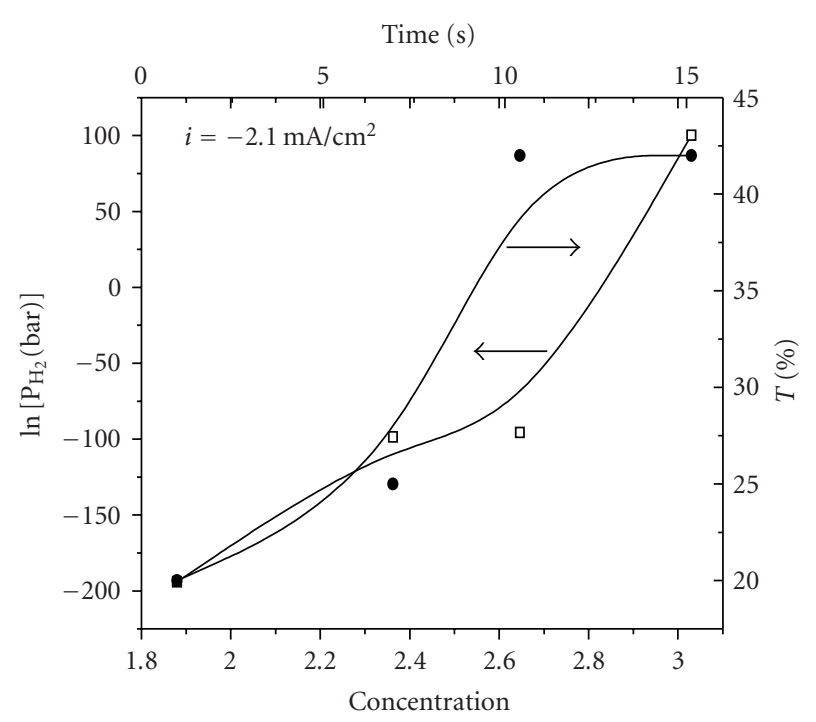

(d)

FIGURE 4: Pressure-concentration isotherms and transmissions as function of concentration at different anodization current densities.

From the plateau pressure corresponding to a coexistence region between two phases fcc and hexagonal, it is possible to estimate the corresponding enthalpy of formation of the high concentration phase with the relation

$$
\Delta \mathrm{H}=\frac{R T}{2}\left[\ln \mathrm{P}_{\mathrm{H}_{2}}-\frac{\mathrm{S}_{\mathrm{H}_{2}}^{0}}{R}\right]
$$

where $\mathrm{S}_{\mathrm{H}_{2}}^{0}=130.8 \mathrm{~J} / \mathrm{K} \mathrm{mol} \mathrm{H}$ is the standard molar entropy of hydrogen gas.

From the unloading pressure-composition isotherm, the enthalpy of formation at $x=2.6$ is $-32.1 \mathrm{~kJ} / \mathrm{mol} \mathrm{H}$ in open circuit condition, while in anodically discharge of hydrogen it is $-48.4 \mathrm{~kJ} / \mathrm{mol} \mathrm{H}$ are in quite agreement with the reported value of $-39.6 \mathrm{~kJ} / \mathrm{mol}$ of $\mathrm{H}$ for the transition during samarium dihydride to trihydride state. Figure 5 shows the variation of enthalpies of formation with different current densities. The enthalpy of formation as shown in Figure 5 is linearly dependent on the current density. From these, one can attribute that the heat obtained by applying $0.2 \mathrm{~mA} / \mathrm{cm}^{2}$ deloading current is $-17.1 \mathrm{~kJ} / \mathrm{mol}$ of $\mathrm{H}$, which is also responsible for producing more stresses between the two phases results in a reorientation of the crystal grains within the film with the (002) direction perpendicular to the substrate. The induced stresses which is also responsible for fast desorption of hydrogen can be clearly seen by sharp decrease in 


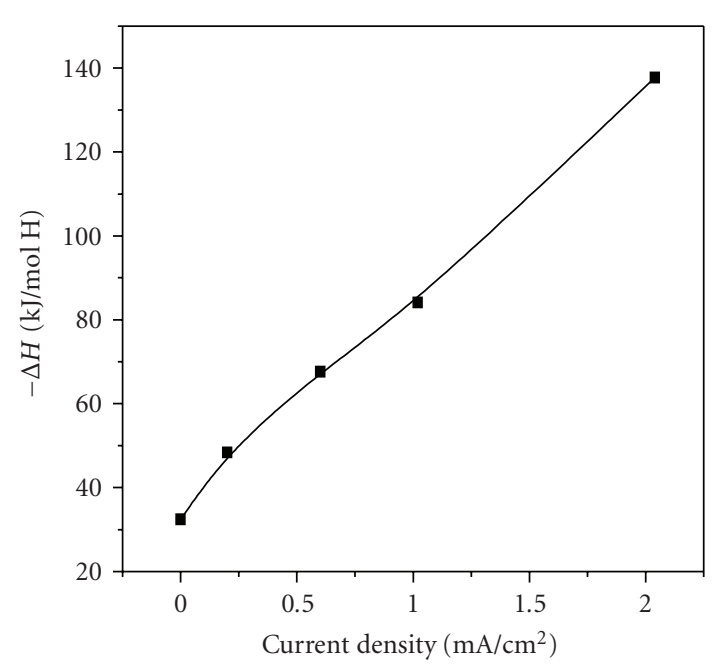

Figure 5: The applied current dependence of the formation enthalpy of Pd (10 nm) capped Sm $(55 \mathrm{~nm})$ film at $\mathrm{C}_{\mathrm{H}}=2.6$.

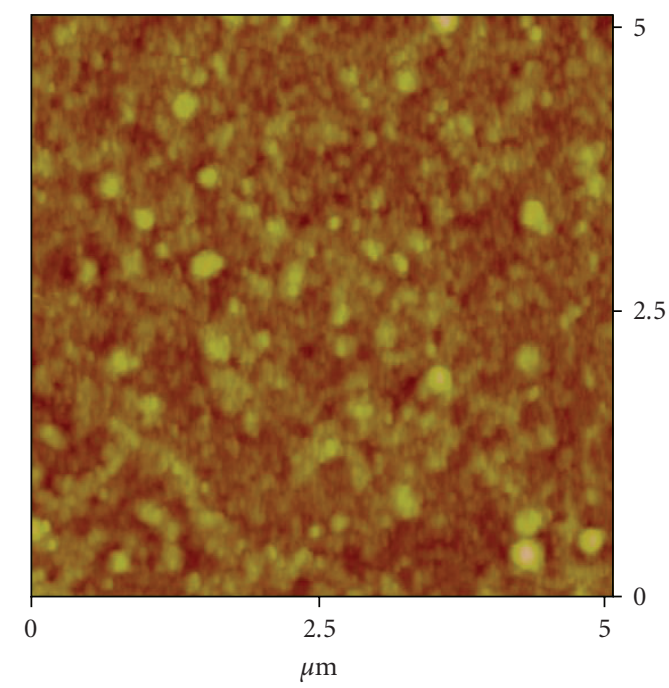

(a)

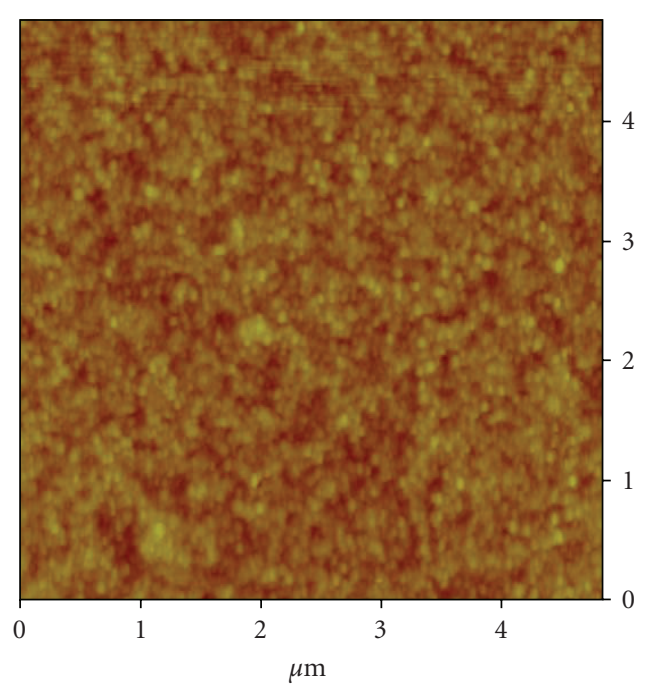

(b)

FIGURE 6: Surface morphology of Pd (10 nm) capped Sm (55 nm) hydrogen unloaded films (a) in self-discharged condition (b) in anodically discharged condition.

transmittance in anodically discharged sample compared to in open circuit discharged sample. The effect of current density was also seen in surface morphology of the hydrogen unloaded samples. Figures 6(a) and 6(b) show the surface morphology of hydrogen unloaded samples in open circuit and anodically discharged condition, respectively. There is a decrease both in rms roughness as well as crystallite size of Pd in anodically discharged sample compared to self-discharged. The rms roughness and particle size in self-discharged sample of $4.6 \mathrm{~nm}$ and $13 \mathrm{~nm}$, respectively, decrease to $2.6 \mathrm{~nm}$ and $8 \mathrm{~nm}$ in anodically discharged sample. This decrease in both rms roughness and particle size can be due to the induced stress, developed in the film during anodically discharged of hydrogen, and is relieved through the rearrangement of the crystal grain within the sample.

The transition time $\tau$ decreases with increasing current density. This dependence is in agreement with Sand's equation

$$
\tau^{1 / 2}=\frac{n F A \pi^{1 / 2} D^{1 / 2} c_{H}}{2 i},
$$

where $D$ is the diffusion coefficient for the $\mathrm{H}$ atoms in the Sm film, $A$ is the electrode surface area, and $\mathrm{C}_{\mathrm{H}}$ is the hydrogen concentration. The latter was evaluated using the Faraday's law from the amount of charge supplied during different charging periods. It was found that the diffusion 


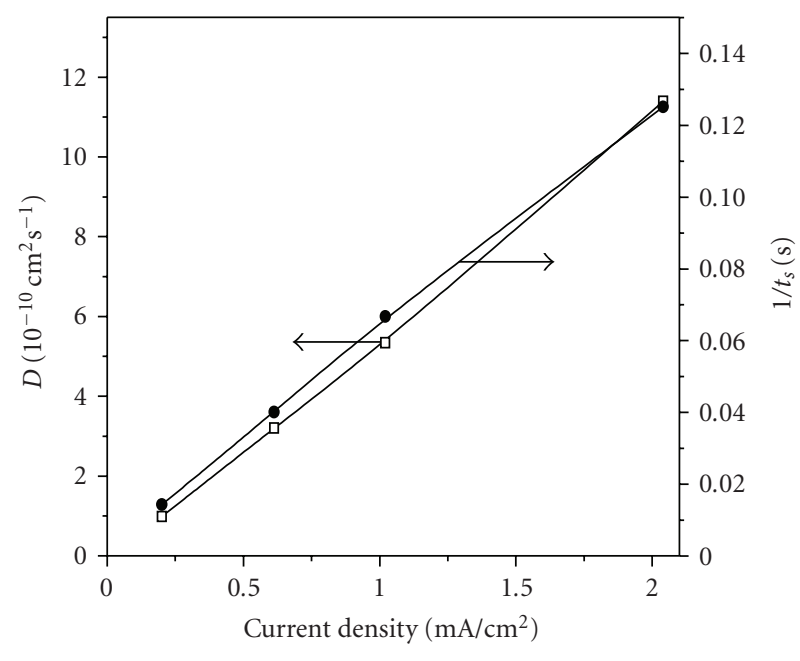

FIgURE 7: The applied current dependence of the diffusion coefficient and the reciprocal response time of Pd $(10 \mathrm{~nm})$ capped Sm $(55 \mathrm{~nm})$ film.

coefficient of hydrogen in Sm film varied with current density. Figure 7 shows the diffusion coefficient as a function of the applied current density. The diffusion coefficient increases from $9.9 \times 10^{-10}$ to $11.0 \times 10^{-10} \mathrm{~cm}^{2} / \mathrm{s}$ in the current density range from 0.2 to $2.04 \mathrm{~mA} / \mathrm{cm}^{2}$. This is of the same order as the diffusion coefficient of hydrogen in other rare earth metal films $10^{-10}$ to $10^{-12} \mathrm{~cm}^{2} / \mathrm{s}$ [9]. The response time decreases from 70 to 8 seconds with increasing current density. The reciprocal response time as shown in Figure 7 is also clearly inversely dependent on the current density.

\section{CONCLUSIONS}

It was shown that nanocrystalline Pd capped Sm films can be reversibly switched between the metallic reflecting dihydride state to semiconducting transparent (in the visible part of electromagnetic spectrum) nearly trihydride state by loading/deloading hydrogen by Galvanostatic means. Pressureconcentration isotherms of $\mathrm{SmH}_{x}$ clearly show formation plateaus. The formation of enthalpy, switching time, and diffusion coefficient has been shown to vary with applied current density. From the onset of the transmission in the isotherms, it was concluded that the deloading of hydrogen from trihydride state coincides with the transmittance decrease in plateau region, and it is therefore the final process to occur during optical switching.

\section{REFERENCES}

[1] W. M. Mueller, J. P. Blackledge, and G. G. Libowitz, Metal Hydrides, Academic Press, New York, NY, USA, 1998.

[2] J. N. Huiberts, R. Griessen, J. H. Rector, et al., "Yttrium and lanthanum hydride films with switchable optical properties," Nature, vol. 380, no. 6571, pp. 231-234, 1996.

[3] R. Eder, H. F. Pen, and G. A. Sawatzky, "Kondo-lattice-like effects of hydrogen in transition metals," Physical Review B, vol. 56, no. 16, pp. 10115-10120, 1997.
[4] P. J. Kelly, J. P. Dekker, and R. Stumpf, "Theoretical prediction of the structure of insulating $\mathrm{YH}_{3}$," Physical Review Letters, vol. 78, no. 7, pp. 1315-1322, 1997.

[5] K. K. Ng, F. C. Zhang, V. I. Anisimov, and T. M. Rice, "Theory for metal hydrides with switchable optical properties," Physical Review B, vol. 59, no. 8, pp. 5398-5413, 1999.

[6] J. W. J. Kerssemakers, S. J. van der Molen, N. J. Koeman, R. Günther, and R. Grlessen, "Pixel switching of epitaxial $\mathrm{Pd} / \mathrm{YH}_{x} / \mathrm{CaF}_{2}$ switchable mirrors," Nature, vol. 406, no. 6795, pp. 489-491, 2000.

[7] M. Kremers, N. J. Koeman, R. Griessen, et al., "Optical transmission spectroscopy of switchable yttrium hydride films," Physical Review B, vol. 57, no. 8, pp. 4943-4949, 1998.

[8] E. S. Kooij, A. T. M. van Gogh, and R. Griessen, "In situ resistivity measurements and optical transmission and reflection spectroscopy of electrochemically loaded switchable $\mathrm{YH}_{\mathrm{x}}$ films," Journal of the Electrochemical Society, vol. 146, no. 8, pp. 2990-2994, 1999.

[9] M. Di Vece, I. Swart, and J. J. Kelly, "Electrochemical kinetics of hydrogen intercalation in gadolinium switchable mirrors," Journal of Applied Physics, vol. 94, no. 7, pp. 4659-4664, 2003.

[10] I. A. M. E. Giebels, J. Isidorsson, and R. Griessen, "Highly absorbing black $\mathrm{Mg}$ and rare-earth-Mg switchable mirrors," Physical Review B, vol. 69, no. 20, Article ID 205111, 11 pages, 2004.

[11] M. Ouwerkerk, "Electrochemically induced optical switching of $\mathrm{Sm}_{0.3} \mathrm{Mg}_{0.7} \mathrm{H}_{x}$ thin layers," Solid State Ionics, vol. 113-115, pp. 431-437, 1998.

[12] T. J. Richardson, J. L. Slack, R. D. Armitage, R. Kostecki, B. Farangis, and M. D. Rubin, "Switchable mirrors based on nickel-magnesium films," Applied Physics Letters, vol. 78, no. 20, pp. 3047-3049, 2001.

[13] K. Yoshimura, Y. Yamada, and M. Okada, "Optical switching of Mg-rich Mg-Ni alloy thin films," Applied Physics Letters, vol. 81, no. 25, pp. 4709-4711, 2002.

[14] J. L. M. van Mechelen, B. Noheda, W. Lohstroh, et al., "Mg-Ni$\mathrm{H}$ films as selective coatings: tunable reflectance by layered hydrogenation," Applied Physics Letters, vol. 84, no. 18, pp. 36513653, 2004.

[15] F. J. A. Den Broeder, S. J. van der Molen, M. Kremers, et al., "Visualization of hydrogen migration in solids using switchable mirrors," Nature, vol. 394, no. 6694, pp. 656-658, 1998.

[16] K. von Rottkay, M. Rubin, and P. A. Duine, "Refractive index changes of Pd-coated magnesium lanthanide switchable mirrors upon hydrogen insertion," Journal of Applied Physics, vol. 85, no. 1, pp. 408-413, 1999.

[17] J. W. J. Kerssemakers, S. J. van der Molen, R. Günther, B. Dam, and R. Griessen, "Local switching in epitaxial $\mathrm{YH}_{x}$ switchable mirrors," Physical Review B, vol. 65, no. 7, Article ID 075417 , 8 pages, 2002.

[18] A. Remhof, J. W. J. Kerssemakers, S. J. van der Molen, and R. Griessen, "Hysteresis in $\mathrm{YH}_{x}$ films observed with in situ measurements," Physical Review B, vol. 65, no. 5, Article ID 054110, 8 pages, 2002.

[19] I. Aruna, B. R. Mehta, and L. K. Malhotra, "Faster H recovery in Pd nanoparticle layer based Gd switchable mirrors: sizeinduced geometric and electronic effects," Applied Physics Letters, vol. 87, no. 10, Article ID 103101, 3 pages, 2005.

[20] S. Enache, T. Leeuwerink, A. F. T. Hoekstra, et al., "Electrical and optical properties of epitaxial $\mathrm{YH}_{x}$ switchable mirrors," Journal of Alloys and Compounds, vol. 397, no. 1-2, pp. 9-16, 2005. 
[21] P. H. L. Notten, M. Kremers, and R. Griessen, "Optical switching of Y-hydride thin film electrodes. A remarkable electrochromic phenomenon," Journal of the Electrochemical Society, vol. 143, no. 10, pp. 3348-3353, 1996.

[22] K. von Rottkay, M. Rubin, F. Michalak, et al., "Effect of hydrogen insertion on the optical properties of Pd-coated magnesium lanthanides," Electrochimica Acta, vol. 44, no. 18, pp. 3093-3100, 1999.

[23] E. S. Kooij, A. T. M. van Gogh, D. G. Nagengast, N. J. Koeman, and R. Griessen, "Hysteresis and the single-phase metalinsulator transition in switchable $\mathrm{YH}_{x}$ films," Physical Review B, vol. 62, no. 15, pp. 10088-10100, 2000.

[24] P. van der Sluis, "Chemochromic optical switches based on metal hydrides," Electrochimica Acta, vol. 44, no. 18, pp. 30633066, 1999.

[25] C. Christofides and A. Mandelis, "Solid-state sensors for trace hydrogen gas detection," Journal of Applied Physics, vol. 68, no. 6, pp. R1-R30, 1990.

[26] P. Kumar, R. Philip, G. K. Mor, and L. K. Malhotra, "Influence of palladium overlayer on switching behaviour of samarium hydride thin films," Japanese Journal of Applied Physics, vol. 41, no. 10, pp. 6023-6027, 2002.

[27] P. Kumar and L. K. Malhotra, "Electrochemical loading of hydrogen in palladium capped samarium thin film: structural, electrical, and optical properties," Electrochimica Acta, vol. 49, no. 20, pp. 3355-3360, 2004.

[28] J. N. Huiberts, J. H. Rector, R. J. Wijngaarden, et al., "Synthesis of yttriumtrihydride films for ex-situ measurements," Journal of Alloys and Compounds, vol. 239, no. 2, pp. 158-171, 1996. 

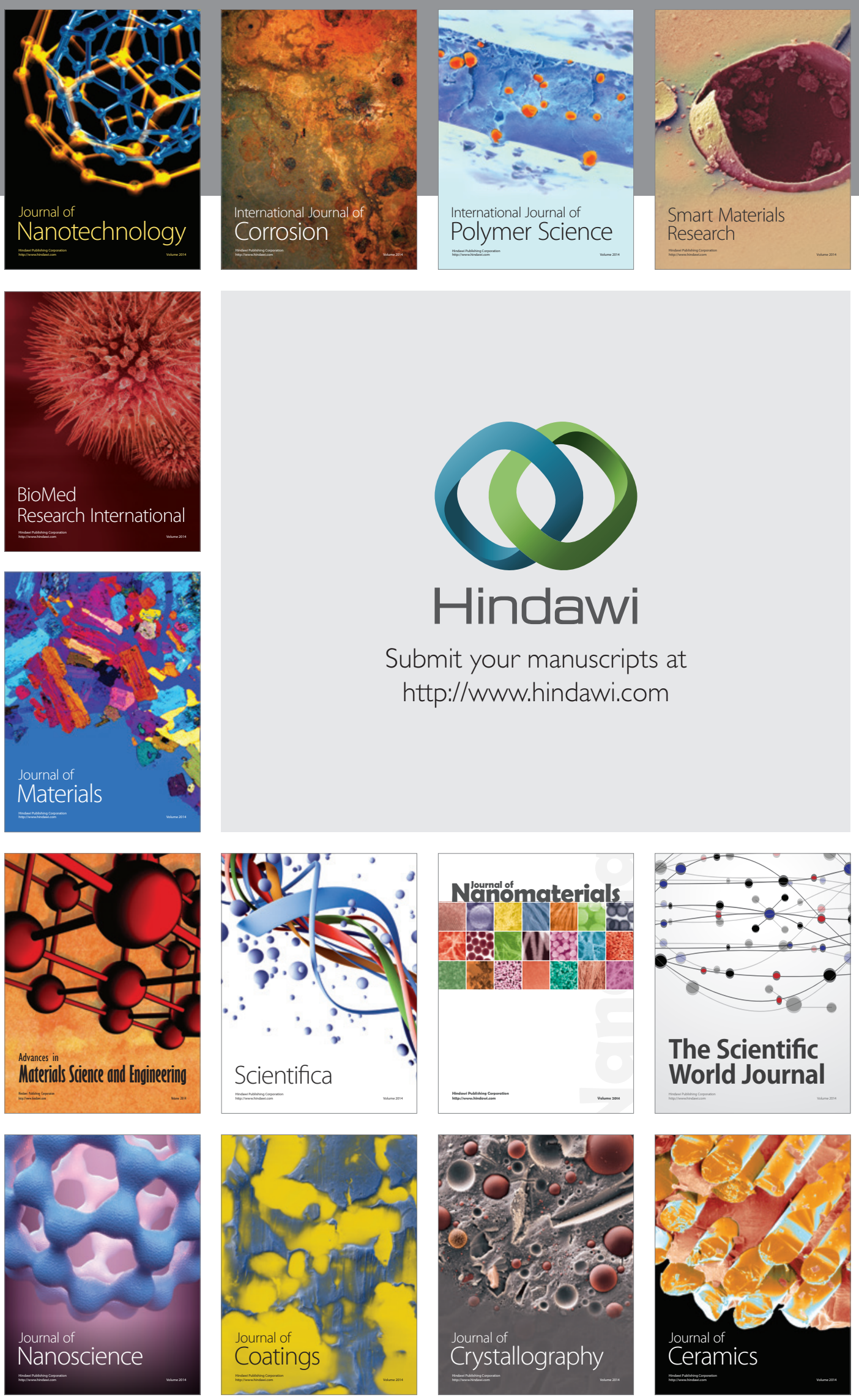

The Scientific World Journal

Submit your manuscripts at

http://www.hindawi.com

\section{World Journal}

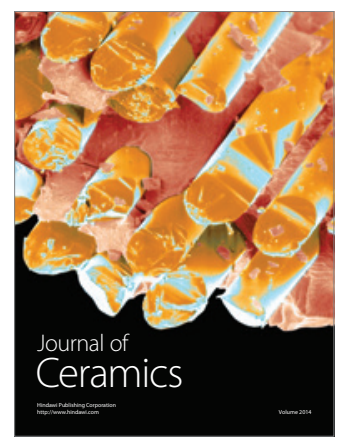

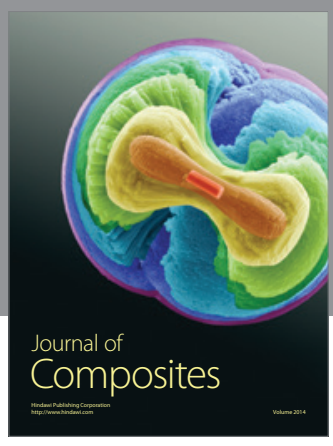
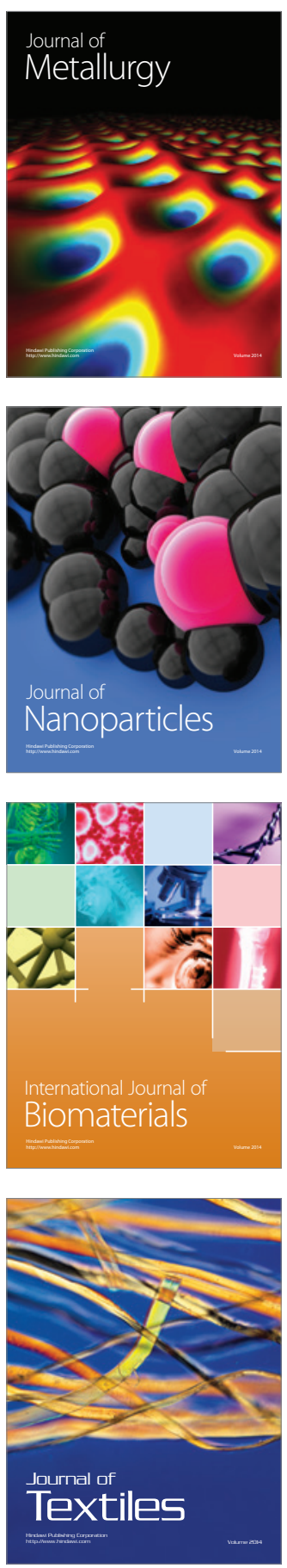